Rev. Latinoam. Psicopat. Fund., São Paulo, 18(1), 33-46, mar. 2015

http://dx.doi.org/10.1590/1415-4714.2015v18n1p33.3

\title{
Lugares de la negación en la obra freudiana*1
}

Niklas Bornhauser*2

Pablo Rosales*3

La negación es un concepto relevante para el psicoanálisis. Suele pensarse como una reacción defensiva frente a aquello que surge desde el inconsciente y amenaza la estructura simbólica que rige sobre la consciencia. Sin embargo, la negación puede ser concebida como una operación compleja, que obedece no sólo a uno, sino a múltiples territorios simbólicos. Una lectura transversal permite conjeturar que la negación puede ser pensada no solo como condición de emergencia para lo reprimido, sino también como puntapié inicial para la producción subjetiva en sí.

Palabras clave: Negación, Freud, inconsciente, lenguaje, orden simbólico

*1 Este texto fue redactado en el marco del Núcleo de investigación DI-446-13/N "Acciones colectivas en Chile (2013-2015).

*2 Universidad Andres Bello (Santiago de Chile, Chile).

${ }^{* 3}$ Universidad Andres Bello (Santiago de Chile, Chile). 


\section{Introducción}

El psicoanálisis es una práctica discursiva heterogénea, plural y múltiple, que se remonta a diferentes orígenes y en cuyo sinuoso devenir convergen diferentes prácticas, saberes y disciplinas. Los textos freudianos, diversos en cuanto a formatos, estilos y hechura, son el testimonio de la apertura disciplinar, la disposición al diálogo y la voluntad de interrogar los límites preestablecidos del canon científico clásico. Es precisamente esta propiedad la que permite subrayar la importancia de la relación que Freud establece con los campos de la lengua y el lenguaje, ambas estructuras determinantes para la práctica del psicoanálisis y su formulación teórica. Respecto de lo segundo, Georges-Arthur Goldschmidt, célebre traductor de Friedrich Nietzsche y de Peter Handke al francés, en Quand Freud voit la mer: Freud et la langue allemande (2006), no solamente ha subrayado la sensibilidad de Sigmund Freud hacia el alemán, sino que ha destacado tambien la incidencia de determinadas propiedades estructurales del idioma alemán en el forjamiento de los conceptos freudianos. Los campos problemáticos relacionados con este proceso son varios: Primero, la traducción francamente errónea o inconsistente de determinados términos, lo que contribuye a crear una confusión conceptual considerable. La traducción de Trieb como «instinto» hecha por Luis López-Ballesteros junto con Ludovico Rosenthal, es el ejemplo más paradigmático de este orden de problemas. Segundo, el problema de la intraducibilidad de ciertas expresiones literales. Como ejemplo de ello valga el ensayo freudiano Das Unheimliche (1919), especialmente la primera parte, dedicada a rastrear las diferentes traducciones en castellano, inglés y francés, principalmente, y su articulación con el análisis, eminentemente lingüístico, de la composición de la palabra en la segunda parte. Tercero, el efecto sobre la articulación particular, permitida por la lengua alemana, entre el estilo freudiano y el género en el que se inscriben sus escritos. Así, por ejemplo, la traducción al castellano hecha por Luis López-Ballesteros, es considerada de mayor fidelidad al estilo literario de Freud, versus la traducción de José Luis Etcheverry, más cercana a la prosa científica habitualmente empleada en las ciencias naturales. Cuarto, la proporción, en los textos freudianos, entre la coloquialidad o proximidad al lenguaje común y silvestre versus su tecnicidad o idiolecto experto. La crítica de Nikolas Rose (1996) a la expertise de las disciplinas psi y la generación 
de un lenguaje nuevo para interpretar e identificar determinadas problemáticas, por ejemplo, podrían ser un argumento a favor de la denuncia del uso excesivo de palabras técnicas y, en su lugar, un alegato a favor de una traducción accesible a lectores no especializados. Estos campos problemáticos ponen de manifiesto las posibilidades e imposibilidades que implican, en la traducción, la ineludible reconstrucción del texto y la apertura de nuevos espacios para las transformaciones estructurales de la obra y su posterior desarrollo como discurso. En el caso de los escritos freudianos, la lengua alemana predispone y habilita el surgimiento de conceptos, cuyas acepciones guardan íntima relación con la morfología, sintaxis, ortografía y prosodia del alemán. Tal es la particularidad que se observa en el caso de la Verneinung, término utilizado recurrentemente en el psicoanálisis freudiano para designar la función psíquica que opera como requisito de la admisión de lo reprimido en la consciencia y cuyo desarrollo histórico nos proponemos revisar a continuación. ${ }^{1}$ La hipótesis que guía nuestra lectura es doble: primero, las significaciones conceptuales de la Verneinung se enlazan estrechamente con la forma de su expresión, modificando así su valor operativo en el cuerpo teórico y práctico psicoanalítico. Segundo, la negación, en sentido estrecho, puede ser considerada como una función intelectual-defensiva, ligada al trabajo de la represión que la precede lógica y cronológicamente. No obstante, el concepto posee en la obra freudiana un desarrollo histórico que sugiere concebirla como una operación singular de valor productivo presente no en una, sino en múltiples dimensiones de la labor psíquica.

\section{Traducciones y representaciones de la Negación}

La negación (die Verneinung), como término atingente al desarrollo del psicoanálisis freudiano, aparece habitualmente representada en su traducción a la lengua española a través de tres palabras: "negación", "denegación" y "renegación", siendo las dos primeras de común aparición en las obras completas de Freud traducidas por José Luis Etcheverry, mientras que la última aparecerá más bien ligada al desarrollo de la obra de autores posteriores, como Jaques Lacan, quien utiliza ampliamente este término para designar el modo de resolución del complejo de Edipo en las estructuras perversas. La ausencia de los términos "renegar" y "renegación" en la traducción de Etcheverry, sin embargo, se debe a la elección de las

${ }^{1}$ Este seguimiento será llevado a cabo utilizando las Obras Completas en español. 
palabras "desmentida" y "desmentir" para el sustantivo Verleugnung y el verbo verleugnen, respectivamente, las cuales el traductor considera de mejor correspondencia al contexto en que se presentan los conceptos en la lengua original. Verleugnen — literalmente des-mentir — en alemán habitualmente es empleado para distanciarse enérgicamente de algo o alguien, es decir, para no comprometerse, garantizar o respaldar algo o alguien. De este modo, es posible, verleugnen sus ideales, sus amigos, a sí mismo. También se emplea como doble negación, es decir, nicht verleugnen, como para referir a la imposibilidad de verleugnen sus orígenes, su procedencia, ciertos hechos indiscutibles etc. De ahí que en otras traducciones y obras posteriores a Freud también traducidas a la lengua española, se halle a la "renegación" como equivalente de la "desmentida".

El segundo término empleado en la traducción al castellano es el vocablo “denegación”. En este caso, la traducción de Etcheverry se aplica sobre los términos Versagen y Versagung, los cuales se interpretan como "denegar", "denegación" y "frustración", según sea atinente. Versagen — literalmente: des-decir — alude a dos campos de significación: por un lado, fracasar, fallar, no cumplir; y por el otro, rehusar, rechazar, privar de. De todas formas, el concepto de la denegación hace referencia a la imposibilidad, por parte del sujeto, de satisfacer una demanda pulsional debido a la presencia de un obstáculo real que se presenta como insuperable.

La tercera y última palabra utilizada para representar esta operación en la traducción de Etcheverry es la "negación" misma, que se presenta en la versión castellana como el equivalente del término original Verneinung al que en 1925 Freud dedica un artículo titulado, precisamente, Die Verneinung y en el cual se vincula esta operación al trabajo mismo de la represión, de cuyos ecos la negación sería parte. Coloquialmente, verneinen, puede significar, primero, negar, decir que no, responder negativamente, no estar de acuerdo con algo o alguien; segundo, negar, en el sentido de abstreiten, desmentir, refutar o contradecir.

\section{Concepciones de la Verneinung: oposiciones correlacionadas y productivas}

El trabajo freudiano sobre la negación — entendida, fundamentalmente, como operación lógica - , publicado en 1925, surge como resultado del largo desarrollo de una concepción psicoanalítica que, según sugiere Etcheverry, ocurre en el margen delimitado por la influencia de las escuelas materialistas derivadas de los postulados de Ernst Haeckel y Emil du Bois-Reymond, durante la segunda mitad del siglo XIX en Alemania. En el apartado "La cultura clásica alemana como contexto" del volumen Sobre la versión Castellana de las obras completas de Freud, Etcheverry subraya la visión reduccionista de los fenómenos naturales de Du Bois-Reymond, 


\section{ARTIGO}

los cuales, en última instancia, se igualan a la acción de fuerzas físico-químicas. Un segundo punto de influencia se encuentra en Haeckel, quien, en oposición a Du Bois-Reymond, propone la existencia de vastos nexos entre los fenómenos de la naturaleza que no podrían observarse bajo el prisma de una visión reduccionista.

Freud, en vez de suscribir uno de los dos postulados, admite ambas ideas y transforma la tensión contradictoria entre ellas en un vínculo correlativo y productivo para el mundo psíquico. De ahí en adelante, buena parte de los postulados freudianos se construyen sobre la base de la existencia supuesta de dos fuerzas fundamentales opuestas y correlacionadas entre sí; la atracción y la repulsión. Un ejemplo medular de la sucesión inaugurada a partir dicha correlación lo constituye el par de opuestos bewusst-unbewusst, consciente e inconsciente, respectivamente. La oposición entre ambos sustratos psíquicos se organiza sobre el prefijo un, que se antepone al tronco bewusst, o sea, consciente. Según el Diccionario de los hermanos Grimm, se trata de una "ursprünglich verneinende untrennbare partikel", es decir, una partícula indisociable, que originaria o primordialmente niega o contradice; por ejemplo, en unheimlich, siniestro en la versión de López-Ballesteros u ominoso según la traducción de Etccheverry, unbewusst, inconsciente, Ungeschehenmachen, término para el cual Laplanche y Pontalis proponen decir anulación retroactiva, o unerkannt, desconocido.

El propio Freud, en Das Unheimliche (1919), rastrea el origen de la marca de lo ominoso, das Unheimliche, precisamente en su opuesto: aquello que antaño fue conocido y familiar, das Heimliche, y que, por ser en extremo incompatible con aquellas representaciones que soportadas en la realidad comenzaron a poblar la urdimbre de lo simbólico, atrajeron sobre si el trabajo de la represión, según el cual su retorno se volvió una amenaza permanente. Es precisamente en y a partir de Das Unheimliche (1919) que Freud concibe a la represión como la fuerza que se halla en el origen de una línea divisoria y constituyente de dos territorios simbólicos incompatibles: lo consciente, por un lado, y lo inconsciente, por otro.

Siguiendo el razonamiento relativo a la coexistencia de polos opuestos e indisociablemente correlacionados, y como consecuencia del continuo desarrollo productivo de la relación entre la consciencia y el inconsciente a raíz de la fractura provocada por la represión, la "negación" se encontrará opuesta y correlacionada a la "aceptación".

\section{Lectura histórica de la Negación}

Un examen genealógico del texto freudiano, sensible a la transformación y redefinición dinámica de los conceptos a través de la cual ésta se desarrolla, subraya 
la importancia de un análisis histórico crítico, sensible a las discontinuidades, los quiebres y las fisuras. ${ }^{2}$ Toda relación con los escritos freudianos que se pretenda productiva y no meramente repetitiva, interesada en generar el soporte de la multiplicidad de interpretaciones posibles, deberá renunciar a la pretensión de establecer una continuidad lineal entre la palabra de su fundador - en este caso, Sigmund Freud - y las interpretaciones puestas en juego por parte de sus lectores. En efecto, a través del estudio de los conceptos cuyo interjuego relacional hace de sostén al psicoanálisis freudiano se advierten una serie de transformaciones que responden en forma dinámica a los nuevos hallazgos clínicos y teóricos, a las nuevas vinculaciones conceptuales $\mathrm{y}$, en definitiva, a todo cuanto sirviera a su desarrollo en un momento específico y obedeciera tanto al propósito de la voluntad y la intención del mismo Freud como a las direcciones que la disciplina psicoanalítica tomaría tras adquirir un importante nivel de independencia y autonomía respecto a la vida misma de su fundador.

El carácter emancipatorio del discurso psicoanalítico, así como su relación crítica con la praxis, no solamente clínica (Bornhauser, 2006), proporcionan una serie de elementos para que la revisión reflexiva de su pensamiento no se circunscriba a momentos privilegiados únicos, sino se torne un principio generativo constante, atento a las contradicciones e incoherencias, capaz de productivizar 38 los errores y desaciertos. Las sucesivas reescrituras de Die Traumdeutung (1900 [1899]), como sostiene Ilse Grubrich-Simitis (2000), son el testimonio vivaz de la inquebrantable voluntad de someter a revisión lo que en otro momento parecía ya sea comprensible de suyo y evidente o garantizado y asegurado por la reflexión psicoanalítica. Otras tantas veces, los conflictos no llegan a resolverse, sino que son postergados y arrojados a un lugar donde no se les admite ni se les desestima, un lugar plástico y productivo para el forjamiento del psicoanálisis como un discurso crítico, sensible a sus propias contradicciones.

El caso de la negación no constituye una excepción. Se trata de una operación que es advertida, por vez primera, en una etapa temprana de la obra freudiana - ya en la última década de $1800-\mathrm{y}$, en consecuencia, posee un extenso y enrevesado desarrollo histórico, cuyas transformaciones, variaciones y desplazamientos, aparte

${ }^{2}$ El corpus freudiano se presenta menos como un texto homogéneo, unitario, monolítico, sino, más bien, como un conjunto complejo, articulado por elementos constituyentes diversos: cartas, conferencias, casos clínicos, ensayos, libros, trabajos científicos clásicos, entre otros. Las relaciones que se pueden establecer entre estos elementos no son únicamente cronológicas o lineales, sino que suponen trabajar con una noción de historia que deje espacio a las discontinuidades y a las rupturas, concibiendo a éstas no como meras suspensiones de una cadena progresiva ininterrumpida, sino pensándolas como cisuras portadoras de un valor positivo y productivo para la generación de conceptos. 


\section{ARTIGO}

de constituir una trama argumentativa relativamente autónoma y sólida, acompañan a otras formulaciones de importancia para el psicoanálisis, como, por ejemplo, la represión.

\section{La desestimación y su escisión}

La silueta de la negación aparece ya en los "Trabajos sobre hipnosis y sugestión" (1886-1889/1979a), en el texto "Hipnosis" (1891), donde Freud señala que "El genuino valor terapéutico de la hipnosis reside en la sugestión que durante ella se imparte. Esta sugestión consiste en la enérgica negación del achaque del que el enfermo se ha quejado, o en el aseguramiento de que él es capaz de hacer cierta cosa, o en la orden de ejecutarla" (p. 143). Sin embargo, Freud no tarda en notar que este efecto sugestivo es transitorio y acaba por desvanecerse, disminuyendo incluso en su duración con cada aplicación. Lejos de insistir, Freud da cuenta de un hecho que repercutirá con fuerza tanto en su obra como en su forma de concebir la histeria: la negación hipnótica, por enérgica que sea, no destruye aquello que es negado, sino que lo empuja hacia otro lugar restableciendo, por un corto periodo, un orden previo donde las quejas sintomáticas eran innecesarias.

Aquello que esta negación tajante desaloja, por ende, acaba siempre por retornar y es que no hay nada en el paciente, más allá de la orden que recibe del médico, que impida la reemergencia del malestar que en su sinuoso recorrido por dichas translaciones no ha perdido nada de su fuerza y empuje originales. Resultará fácil advertir que la negación hipnótica debe su efectividad, por efímera que sea, a un mecanismo que se dirige con toda probabilidad en idéntica dirección y que tiene por finalidad provocar el mismo tipo de desalojo: la represión. Esta última le ha negado el acceso a la consciencia a cierta representación incluso antes de que el sujeto pueda emitir algún tipo de juicio intelectual sobre ella. En consecuencia, lo inadmisible es desalojado y obligado a transformarse de alguna manera antes de intentar retornar en una forma que resulte tolerable para la consciencia y no atraiga sobre si el trabajo de la represión que la negación hipnótica fue capaz de forzar de manera temporal.

En esta etapa inaugural del pensamiento freudiano, años antes de forjar siquiera los que devendrían los cimientos de la fase propiamente psicoanalítica, la negación, que aparece mayoritariamente bajo la forma de "desestimación», Verwerfung, está ligada al esfuerzo de desalojo, werfen, ${ }^{3}$ trazando una línea

${ }^{3}$ Werfen, en alemán, significa lanzar, arrojar, proyectar, echar, tirar. 
de continuidad entre el acto de desestimar una representación inconciliable y desalojarla (rechazarla o arrojarla) como consecuencia de dicha desestimación inaugural. Por lo mismo, la negación en este momento aparece de una forma rudimentaria, es decir, como un juicio automático, previo al trabajo intelectual del pensamiento y mucho más cercana al acto motriz que a los actos del pensamiento propiamente tales. En 1894, en el texto "Las neuropsicosis de defensa", Freud ligará este proceso de desestimación a la génesis de la psicosis alucinatoria, demostrando que la negación se ejerce de manera indiscriminada tanto sobre lo real-objetivo como sobre lo representativo-subjetivo, aunque con diferentes resultados: la alucinación en el primer caso y el síntoma neurótico en el segundo, pero siempre siguiendo la línea de un mecanismo defensivo que se activa frente a un hecho o representación que se percibe como intolerable. La idea de la negación ligada a una forma de mecanismo defensivo prevalecerá, en adelante, superando incluso a la obra de Freud.

Al año siguiente, en 1895, Freud publicará junto a Breuer sus "Estudios sobre la histeria", exponiendo, en el apartado titulado "Sobre la psicoterapia de la histeria", el hecho de que algunos de sus pacientes son capaces de enunciar ideas u ocurrencias conflictivas sólo para después desmentirlas y restarles valor. Si bien se advierte que el uso del término "desmentida" acabará siendo, más adelante, el equivalente de la "renegación" - término que se liga a la génesis de la perversión en Lacan - , en este momento no existe, para Freud, una diferencia clara entre las formas a través de las cuales la negación se manifiesta, siendo así la "desmentida" y la "desestimación" palabras utilizadas indistintamente para designar un conjunto indiferenciado de procesos.

Un segundo momento en esta historia de la negación en el texto freudiano está marcado por la publicación, en 1900, del que ha sido considerado como el texto princeps del psicoanálisis: Die Traumdeutung. A lo largo del libro sobre la interpretación los sueños Freud postula reiteradamente que la negación, a diferencia de lo que sucede en el acaecer psíquico durante la vigilia, no tiene lugar en el sueño. Esta idea, a pesar de las sucesivas transformaciones que sufriría la doctrina de los sueños y el psicoanálisis en general, no solamente se mantendría sino que incluso será reforzada en 1923 con la introducción de la segunda tópica, cuando Freud sostiene que el Ello y el inconsciente en general no conocen ni admiten la negación. Sin embargo, este texto no puede abandonarse sin antes señalar lo que en primera instancia podría aparecer como una contradicción básica: Freud reconoce que el sueño niega y desmiente aquello que desde la percepción se le presenta como obstáculo en el cumplimiento de deseo que plantea en su estructura y desarrollo. Concretamente, en un apartado de La interpretación de los sueños, titulado "El material y las fuentes del sueño: Las fuentes somáticas del sueño", Freud relata un ejemplo, en el cual el soñante se encuentra aquejado por molestos y dolorosos 


\section{ARTIGO}

problemas de salud que le impedían realizar cualquier actividad que involucre un mínimo de movimiento. En el sueño, sin embargo, se presenta él mismo realizando una actividad que ni siquiera disfruta en condiciones normales: la de cabalgar, que en su estado de salud le habría significado, además, exponerse a considerables cantidades de dolor: "La actividad en que me presenta el sueño; es la negación más enérgica que pueda imaginarse del sufrimiento" (Freud, 1900/1979b, p. 242).

Así queda expuesto el hecho de que lo inconsciente, a través del sueño, es capaz de valerse de la operación de la negación, desmintiendo, en este caso, un aspecto de la realidad que interfiere con el cumplimiento del deseo que le sirve como motor. Parece improbable que Freud planteara en el mismo texto y al mismo tiempo que, por un lado, para el inconsciente y sus manifestaciones no existe la negación y que por otro, ejemplificara y enunciara el hecho de que el sueño ejecuta la negación sobre aquello que lo contradice. En consecuencia, han de existir diferencias suficientes como para que Freud considere que la negación, como forma y no como operación, se encuentra presente en un lugar y ausente en otro. Esta diferencia es el principio de una escisión en la línea de desarrollo de la desestimación que llevara a Freud a abordar la operación de la negación desde dos planos diferentes que competen al psicoanálisis y que se diferencian del mecanismo de la represión que fuera observado en principio como un juicio autónomo de desestimación y desalojo.

\section{La negación lógica y la desmentida}

La línea divisoria que se inaugura en La interpretación de los sueños permite concebir la negación como una operación independiente del símbolo lingüístico que la representa; el "No", que como tal, constituye un primer riel de desarrollo teórico para dicha figura en la obra freudiana. Esta primera vía quedara expuesta en 1925, a través del texto que lleva por título "La negación", en el cual Freud establecerá los vínculos entre el "No", como símbolo de la negación y el juicio, como función intelectual del Yo.

Freud señalara que "la negación es un modo de tomar noticia de lo reprimido" (Freud, 1925/1979i, p. 253) sin que ello signifique entregarle a tales enunciados la veracidad a la que podrían aspirar de no hallarse esta negación del lado de una represión que prevalece en lo esencial de su trabajo. Aún así, la negación lógica difiere de la represión en el tiempo de su ocurrencia: si bien el "No" marca la existencia de un pensamiento que por preferencia podría ser reprimido, el desalojo tajante de las representaciones que caracteriza a la represión y antecede al juicio, no ocurre, dejando disponible a la consciencia y sus operaciones el contenido de las ocurrencias negadas. La negación lógica entonces, se caracteriza porque obedece 
tanto al imperio de la realidad como al dictamen de la represión y se ejerce, como operación, sobre el plano de las representaciones simbólicas.

Otra vía de desarrollo para la operación de la negación en la obra freudiana se presenta a través de los trabajos que enuncian la operación de la desmentida (renegación) y que siguen la lógica ya expuesta en La interpretación de los sueños (1900 [1899]), es decir, que no operan sobre el pensamiento y sus símbolos — lo cual, en principio, podría designarse como el polo subjetivo — , sino sobre lo real percibido como objetivo y a favor del cumplimiento de un deseo cuya frustración (denegación) resulta intolerable. Deviene entonces un fallo en el juicio de realidad que se ve sobrepasado por la primacía del deseo que gobierna en lo inconsciente, muy diferente de la resolución que el inconsciente ensaya con regularidad en la neurosis, caso en el que el deseo, al verse reprimido por las estructuras de representaciones que gobiernan en la consciencia, transmuta aquello que fue desestimado y desalojado en un síntoma admisible.

Los textos que se hallan en esta línea de trabajo son numerosos y sus representantes más destacados son susceptibles de ser hilados, aunque no necesariamente de modo continuo, a lo largo de un filamento cuyo inicio puede ubicarse en el texto "Complemento metapsicológico a la doctrina de los sueños" (1917[1915]). En dicho texto Freud indica, a propósito de la amentia, que ésta "es la reacción frente a una pérdida que la realidad asevera pero que debe ser desmentida \{Verleugnung\} por el yo como algo insoportable" (Freud, 1917/1979f, p. 232) y que tiene por efecto el ulterior desconocimiento por parte del yo de la realidad. Diez años después, en "El fetichismo", Freud explica esta operación - a la cual inscribe en la lógica de la perversión - como un esfuerzo por desmentir (renegar de) la pérdida del falo, reubicando su valor en otro objeto alternativo que aparece como prueba tangible de la inefectividad de la castración. Por último, en "La escisión del yo en el proceso defensivo" (1940[1938]/19791), Freud establece la probabilidad de un vínculo entre la desmentida y el yo en el caso de la neurosis, aun que el texto queda inconcluso, siendo retomado de manera parcial en "Esquema del psicoanálisis" (1940[1938]).

El valor de la desmentida en la obra freudiana, sin embargo, no se reduce a la producción de la perversión, las psicosis alucinatorias o la escisión del yo en la neurosis. Algunos de sus textos rescatan el valor que la desmentida posee en la producción cultural. En el apartado "Nuestra actitud hacia la muerte" del texto "De guerra y muerte. Temas de actualidad" (1915/1979e), Freud pone de manifiesto que la muerte, al igual que la mayoría de los obstáculos que se interponen entre el deseo y su realización, no tiene lugar en lo inconsciente. Lo anterior no sólo tiene consecuencias en la configuración psíquica de los sujetos, sino que resulta relevante en aquellas producciones culturales que están ligadas al esfuerzo de desmentir la muerte como el fin de la existencia, siendo la religión, en buena parte, un esfuerzo por desmentir la mortalidad a la que toda vida está enfrentada. 


\section{ARTIGO}

\section{Síntesis y discusión}

Las particularidades presentes en la traducción de la obra freudiana al español, permiten establecer, en primera instancia, un vínculo semántico entre tres conceptos que originalmente se utilizan para designar funciones propias de diferentes territorios psíquicos; la denegación, la negación y la desmentida (renegación). Esta vinculación, que se hace evidente precisamente en la reconstrucción productiva que implica la traducción de los textos freudianos, permite tambien efectuar una revisión de la génesis y el desarrollo histórico de dichos términos en la que se descubre la posibilidad de separar la función de la negación del símbolo que la representa y establecer así un vinculo operativo entre los conceptos.

El concepto Verleugnung, ya sea que se encuentre traducido a cualquiera de los términos, "renegación" o "desmentida", contiene y conserva en su forma operativa una primera manera de distinción válida para toda forma de negación: Sólo puede negarse aquello que por alguna vía ha alcanzado primero el reconocimiento que admite y, por lo tanto, asevera su existencia en el plano de lo simbólico. La negación, entonces, es siempre una acción simbólica, puesto que opera precisamente sobre aquello cuya existencia se ha admitido primero en la trama de los símbolos.

De esta forma, es posible concluir que la Verneinung no tiene un sentido ni una traducción únicas. Su acepción, más que estar ligada a un significado esencial puro e indiviso, dependerá de sus condiciones de enunciación y de los usos asociados. De modo adicional, la traducción se entrelaza con distintos conceptos, estableciendo relaciones de convergencia y repulsión, de juntura y rechazo, de afinidad y de aversión. Lejos de conformar un concepto secundario o derivado, se convierte en el punto de partida - o de llegada - de una serie de reflexiones relevantes para la comprensión del psicoanálisis. Las pesquisas genealógicas, lejos de agotar el asunto, demuestran ser un abordaje productivo a la hora de desenterrar algunas claves de las diferentes lecturas posibles.

\section{Referencias}

Bornhauser, N. (2006). Acerca de la función emancipatoria y el estatuto crítico de la interpretación. De la voluntad de interpretación hacia una ética psicoanalítica. Alpha, 28, 251-268.

Etcheverry, J. L. (1978). Sobre la versión castellana. In J. Strachey (Ed.) y J.L. Etcheverry (Trad.), Obras completas: Sigmund Freud. Buenos Aires: Amorrortu.

Freud, S. (1979a). Trabajos sobre hipnosis y sugestión: hipnosis. In J. Strachey (Ed.) y J.L. Etcheverry (Trad.), Obras completas: Sigmund Freud (vol. I, pp. 133-146). Buenos Aires: Amorrortu. (Trabalho original publicado em (1886-1889/1891). 
Freud, S. (1979b). La interpretación de los sueños: el material y las fuentes del sueño. In J. Strachey (Ed.) y J.L. Etcheverry (Trad.), Obras completas: Sigmund Freud (vol. IV, pp. 178-284). Buenos Aires: Amorrortu. (Trabalho original publicado em 1900).

Freud, S. (1979c). Sobre el sentido antitético de las palabras primitivas. In J. Strachey (Ed.) y J.L. Etcheverry (Trad.), Obras completas: Sigmund Freud (vol. XI, pp. 143-153). (Trabalho original publicado em 1910).

Freud, S. (1979d). Lo inconsciente. In J. Strachey (Ed.) y J.L. Etcheverry (Trad.), Obras completas: Sigmund Freud (vol. XIV, pp. 153-213). Buenos Aires: Amorrortu. (Trabalho original publicado em 1915).

Freud, S. (1979e). De guerra y muerte. Temas de actualidad. In J. Strachey (Ed.) y J.L. Etcheverry (Trad.), Obras completas: Sigmund Freud (vol. XIV, pp. 274-303). Buenos Aires: Amorrortu. (Trabalho original publicado em 1915).

Freud, S. (1979f). Complemento metapsicológico de la doctrina de los sueños. In J. Strachey (Ed.) y J.L. Etcheverry (Trad.), Obras completas: Sigmund Freud (vol. XIV, pp. 226-233). Buenos Aires: Amorrortu. (Trabalho original publicado em 1917).

Freud, S. (1979g). Lo Ominoso. In J. Strachey (Ed.) y J.L. Etcheverry (Trad.), Obras completas: Sigmund Freud (vol. XVII, pp. 215-251). Buenos Aires: Amorrortu. (Trabalho original publicado em 1919).

Freud, S. (1979h). La pérdida de realidad en la neurosis y la psicosis. In J. Strachey (Ed.) y J.L. Etcheverry (Trad.), Obras completas: Sigmund Freud (vol. XIX, pp. 189-197). Buenos Aires: Amorrortu. (Trabalho original publicado em 1924).

Freud, S. (1979i). La negación. In J. Strachey (Ed.) y J.L. Etcheverry (Trad.), Obras completas: Sigmund Freud (vol. XIX, pp. 249-257). Buenos Aires: Amorrortu. (Trabalho original publicado em 1925).

Freud, S. (1979j). Fetichismo. In J. Strachey (Ed.) y J.L. Etcheverry (Trad.), Obras completas: Sigmund Freud (vol. XXI, pp. 141-152). Buenos Aires: Amorrortu. (Trabalho original publicado em 1927).

Freud, S. (1979k). Moisés y la religión monoteísta. In J. Strachey (Ed.) y J.L. Etcheverry (Trad.), Obras completas: Sigmund Freud (vol. XXIII, pp. 1-132). Buenos Aires: Amorrortu. (Trabalho original publicado em 1939[1934-1938]).

Freud, S. (19791). La escisión del yo en el proceso defensivo. In J. Strachey (Ed.) y J.L. Etcheverry (Trad.), Obras completas: Sigmund Freud (vol. XXIII, pp. 271-178). Buenos Aires: Amorrortu. (Trabalho original publicado em 1940[1938]).

Goldschmidt, G.-A. (2006). Quand Freud voit la mer: Freud et la langue allemande. Paris: Buchet-Chastel.

Grubrich-Simitis, I. (2000). Metamorphosen der Traumdeutung. In J. Starobinski; I. Grubrich-Simitis, y M. Solms. Hundert Jahre Traumdeutung von Sigmund Freud. Drei Essays (pp. 49-100). Frankfurt a. M.: Fischer.

Rose, N. (1996). Inventing Our Selves: Psychology, Power and Personhood. Cambridge: Cambridge University Press. 


\section{ARTIGO}

\section{Resúmenes}

(Lugares da negação na obra freudiana)

A negação é um conceito importante para a psicanálise. Pode ser pensada como uma reação defensiva frente àquilo cuja emergência desde o inconsciente ameaça à estrutura simbólica que legisla sobre a consciência. A negação, no entanto, pode ser concebida como uma operação complexa que obedece não só a um, mas a múltiplos territórios simbólicos. Uma leitura transversal permite conjeturar que a negação pode ser pensada não apenas como condição de emergência para o recalcamento, mas também como ponto de partida para a produção subjetiva em si.

Palavras-chave: Negação, Freud, inconsciente, linguagem, ordem simbólica

\section{(Places of denial in Freud's work)}

Denial is an important concept in psychoanalysis. It is often thought of as a defensive reaction against that which emerges from the unconscious and threatens the symbolic structure that legislates on consciousness. However, denial can be conceived as a complex operation that obeys not only one, but multiple symbolic territories. A cross-reading allows conjecturing that denial can be thought of not only as a condition for the emergence of the repressed, but also as a starting point for the production of subjectivity.

Keywords: Denial, Freud, unconscious, language, symbolic order

\section{(Lieux de négation dans l'oeuvre de Freud)}

La négation est un concept de grande importance pour la psychanalyse. On peut la penser comme une réaction défensive pour faire face à ce qui surgit de l'inconscient et menace la structure symbolique qui régit la conscience. Néanmoins, la négation peut être conçue comme une opération complexe qui obéit non pas à un seul territoire, mais à plusieurs territoires symboliques. La lecture transversale permet de conjecturer que la négation peut être pensée non seulement comme condition d'émergence du refoulement, mais aussi comme point de départ pour la production subjective en soi.

Mots clés: Négation, Freud, inconscient, langue, ordre symbolique

\section{(Territorien der Verneinung in Freuds Werk)}

Die Verneinung ist ein wichtiges Konzept für die Psychoanalyse. Sie wird häufig als eine defensive Reaktion gedacht, auf das, was aus dem Unbewussten hervorbricht und als Bedrohung für die symbolische Struktur empfunden wird, die über das Bewusstsein regiert. Allerdings kann die Verneinung als eine komplexe Operation, die nicht nur einem, sondern mehreren symbolischen Territorien gehorcht, konzipiert werden. Eine transversale Lektüre eröffnet die Vermutung, dass die Verneinung nicht 
nur als Entstehungsbedingung für das Unterdrückte gedacht werden kann, sondern dass sie auch einen Ausgangspunkt für die Produktion des Subjekts darstellt.

Schlüsselwörter: Verneinung, Freud, Unbewusstsein, Sprache, symbolische Ordnung

Citação/Citation: Bornhauser, N., y Rosales, P. (2015, março). Lugares de la negación en la obra freudiana. Revista Latinoamericana de Psicopatologia Fundamental, 18(1), 33-46.

Editores do artigo/Editors: Manoel Tosta Berlinck e Sonia Leite

Recebido/Received: 10.12.2013/ 12.10.2014 Aceito/Accepted: 25.2.2014 / 2.25.2014

Copyright: (C) 2009 Associação Universitária de Pesquisa em Psicopatologia Fundamental/ University Association for Research in Fundamental Psychopathology. Este é um artigo de livre acesso, que permite uso irrestrito, distribuição e reprodução em qualquer meio, desde que o autor e a fonte sejam citados / This is an open-access article, which permits unrestricted use, distribution, and reproduction in any medium, provided the original authors and sources are credited.

Financiamento/Funding: Os autores declaram não ter sido financiados ou apoiados / The authors have no support or funding to report.

Conflito de interesses/Conflict of interest: Os autores declaram que não há conflito de interesses / The authors have no conflict of interest to declare.

\section{NikLas Bornhauser}

Licenciado em Psicologia; Doctor em filosofia; Universidad Andres Bello (Santiago de Chile, Chile).

Beuron 11940 - Las Condes

Santiago de Chile, Chile

e-mail: niklas.bornhauser@gmail.com

\section{José Pablo Rosales Panes}

Licenciado em Psicologia; Magíster em psicología clínica; Universidad Andres Bello (Santiago de Chile, Chile).

San Bruno 2903 - La Florida

Santiago de Chile, Chile

e-mail: Pablorosales.exe@gmail.com 